\title{
Desempenho reprodutivo de éguas (Equus caballus) Puro-Sangue Inglês na primeira estação de monta
}

\author{
Reproductive performance of Thoroughbred Maiden mares
}

\author{
André Vianna Martins, ${ }^{*}$ Luiz Altamiro Garcia Nogueira*
}

\begin{abstract}
Resumo
O objetivo deste trabalho foi avaliar se o período de permanência no Posto de Monta, a partir do momento em que as éguas virgens Puro-Sangue Inglês encerram a carreira nas pistas de corrida, exerce influência sobre o resultado de prenhez obtida ao final da estação de monta, e observar alguns parâmetros reprodutivos e o comportamento sexual, em nossas condições. Acompanharamse 133 éguas com idades variando entre 3 e 6 anos, alojadas no Posto de Fomento da ACPCCRJ - Teresópolis, RJ, durante as temporadas de monta dos anos de 1987 a 1995. Os animais foram divididos em dois grupos, sendo que o Grupo 1 (G1) englobou as éguas que entraram no Posto de Fomento antes do dia 15 de agosto, e o Grupo 2 (G2), as éguas que chegaram do dia 15 de agosto em diante. Foram anotados dados de rufiação diária seguida de palpação retal associada a exame ultrassonográfico transretal. Do total de éguas acompanhadas $(n=133), 117(87,9 \%)$ ficaram gestantes, sendo que destas, $63(91,3 \%)$ eram do $\mathrm{G} 1 \mathrm{e}$ $54(84,4 \%)$ do $G 2$, sem diferença significativa $(p>0,05)$ entre os dois grupos. O tempo em dias para que as éguas apresentassem o primeiro estro, após sua entrada no Posto de Monta, foi semelhante ( $p>0,05)$ em ambos os Grupos, sendo $23,9 \pm 22,7$ dias para o $\mathrm{G} 1$ e 16,0 $\pm 16,0$ dias para o G2. A duração média do primeiro estro apresentado pelas éguas do $\mathrm{G} 1$ (6,4 $\pm 4,8$ dias) foi igual ( $>0,05)$ a do $G 2(5,9 \pm 4,6$ dias). Das 142 ovulações detectadas por meio de palpação retal 75 (52,8\%) ocorreram nas 24 horas antes do final do estro e $50(35,2 \%)$ nas 48 horas antes do seu término. Em relação ao comportamento sexual no momento da cobertura, das 133 éguas, 78 (58,6\%) foram cobertas normalmente, 31 (23,3\%) se mostraram tímidas diante do garanhão e 22 $(16,5 \%)$ só permitiram a monta após serem sedadas quimicamente, e duas restantes não chegaram a ser cobertas por não desenvolverem atividade ovariana. À rufiação, 10 (7,5\%) éguas não apresentaram qualquer sinal externo de cio. As éguas provenientes do Jockey Club, após encerrarem as atividades turfísticas para iniciarem a reprodução, e que chegaram antes ou durante a temporada oficial de monta, apresentaram percentual de prenhez semelhante. A taxa da gestação, duração do estro e o momento da ovulação foram compatíveis aos descritos previamente na literatura. O comportamento sexual hostil demonstrado por algumas éguas virgens pôde ser contornado com técnicas de manejo adequadas.
\end{abstract}

Palavras-chave: reprodução; fertilidade; éguas virgens.

\begin{abstract}
The objective of this paper was to evaluate whether the period the Thoroughbred maiden mares remained at Posto de Fomento exerted any influence on the pregnance rate obtained at the end of the mounting season after they had retaired from the race tracks. It was also our aim to observe the reproductive patterns and sexual behaviour under our conditions of management. 133 Thoroughbred maiden mares were observed at Posto de Fomento supported by Rio de Janeiro Race Horse Breeders and Owners Association in Teresópolis, during the breeding season from 1987 to 1995 . The mares were divided into Group 1 (G1) and Group 2 (G2). The mares which arrived at Posto de Fomento before August 15th were put together in G1 and in G2 the mares which arrived there from August 15th forth. The data were written down according to daily teasing followed by rectal palpation associated to transrectal ultrasonografic exams. From the total number of animals observed $(n=133), 117(87,9 \%)$ mares became pregnant, $63(91,3 \%)$ belonging to $G 1$ and $54(84,4 \%)$ to $G 2$, there being no significant difference (p>0,05) between the two groups. The time in days for the mares to present their first estrus after their arrival at Posto de Fomento was similar ( $p>0,05)$ in both groups, $23,9 \pm 22,7$ days for $\mathrm{G} 1$ and $16,0 \pm 16,0$ days for $\mathrm{G} 2$. The average duration of the first estrus in $\mathrm{G} 1 \mathrm{mares}(6,4 \pm$ $4,8$ days) was similar ( $p>0,05)$ to $G 2$ mares $(5,9 \pm 4,6$ days). From the total numbers of 142 ovulations detected by means of rectal palpation, $75(52,8 \%)$ ovulations occurred within the 24 hours before the final of the estrus and 52 (35,2\%) ovulations within the 48 hours before the end of heat. In relation to the sexual behaviour at the moment of mount, 78 (58,6\%) mares were normally mounted, $31(23,3 \%)$ became timid in the presence of the stallion and $22(16,5 \%)$ mares could only be mounted after being chemically sedated and the two mares which remained were not mounted because they did not develop any ovarian activity. When exposed to a teasing stallion, 10 (7,5\%) mares did not present any external sign of heat. The result made us observe that the mares which came from Jockey Club before the beginning or during the official breeding season to reproduce, presented a similar percentage of pregnance. The rate of pregnance, duration of estrus and the moment of ovulation were almost equivalent to the ones described in the bibliography consulted. The hostile sexual behaviour shown by some maiden mares could be dealt with proper management.
\end{abstract}

Keywords: reproduction; fertility; maiden mares.

*Faculdade de Veterinária - UFF - Niterói/RJ. 


\section{Introdução}

Nas últimas décadas, uma visão mais dinâmica da reprodução em eqüinos tem sido desenvolvida por diversos especialistas, o que possibilita ao criador alcançar maior produtividade. Para isto tornou-se necessário uma melhor compreensão da fisiologia das éguas reprodutoras, especialmente quando especificamos uma raça, como é o caso do Puro-Sangue Inglês (PSI) que, geralmente, tem sua seleção baseada principalmente em resultados de performance nas pistas de corrida e/ou linhagem. O descaso com os parâmetros de fertilidade na escolha dos reprodutores e matrizes vem mantendo as taxas de gestação e nascimento inferiores às de outras raças. Segundo Bruck et al. (1993), as taxas de gestação em éguas PSI variam de $61,5 \%$ a $88,7 \%$, enquanto os percentuais de nascimento variam de $53,9 \%$ a $72,1 \%$.

A maioria dos trabalhos tem sido realizada em países do hemisfério norte e avaliando-se as éguas de maneira ampla. Existem situações em que se faz necessário um conhecimento específico e individual de cada categoria das reprodutoras, como, por exemplo, das potrancas que são encaminhadas à reprodução. Existe ainda o problema que as potrancas enfrentam antes de tornarem-se reprodutoras, ao passar por um período, muitas vezes extremamente adverso, desempenhando funções atléticas nos hipódromos, onde se encontram em intensa atividade física e sob stress severo.

O início da estação de monta oficial, determinado pelo órgão que regulamenta a criação desta raça, é arbitrário e não coincide com o período de reprodução natural (fisiológica) dos eqüinos. Isso acaba por frustrar as expectativas dos próprios criadores que, motivados por obterem vantagens comerciais, desejam que as éguas estejam gestantes logo no início da temporada de monta.

O objetivo deste trabalho foi verificar se o período de permanência no Posto de Monta, a partir do momento que as potrancas encerram a carreira nas pistas de corrida, exerce influência sobre o resultado de prenhez obtida ao final da estação de monta e procurar contribuir com mais informações a respeito dos parâmetros reprodutivos e do comportamento sexual de éguas virgens da raça Puro-Sangue Inglês, em nossas condições.

\section{Materiais e métodos}

Foram acompanhadas 133 éguas virgens, da raça Puro-Sangue Inglês, com idades variando entre 3 e 6 anos, que após encerrarem as atividades turfísticas, foram alojadas no Posto de Fomento e distribuídas em dois grupos, das quais 69 constituíram o Grupo 1 (G1), e as outras 64 o Grupo 2 (G2). O G1 englobou as éguas que entraram no Posto de Fomento antes do início da estação de monta, isto é, antes do dia 15 de agosto; já o G2 foi composto pelas éguas que chegaram durante o período de monta, ou seja, do dia 15 de agosto a 15 de janeiro dos anos de 1987 a 1995.

Para o exame ginecológico, foi utilizada palpação retal e vaginoscopia, sendo que na temporada de monta de 1995 ,

\footnotetext{
'Aloka - modelo SSD 210 DX II - transdutor linear de 5 Mhz.
}

foi possível utilizar também o exame ultra-sonográfico. ${ }^{1}$ As éguas consideradas aptas para a monta passaram a ser rufiadas diariamente para detecção do cio, avaliando-se o comportamento da fêmea diante da aproximação e assédio do rufião, o qual, neste caso, era um cavalo inteiro e exclusivo para esta função. Se a égua mostrasse sinais de aceitação ao rufião, o que caracterizava o estro, era relacionada em ficha própria. Por outro lado, aquelas éguas em que se constatou uma inatividade ou hipofunção ovariana $(n=69$, sendo 40 do Grupo 1 e 29 do Grupo 2), foram submetidas a um programa de indução de cio através da manipulação do fotoperíodo, que consistiu em uma complementação da luminosidade natural com luz artificial, de forma a completar um total de 16 horas de luz por dia. Para isto, as éguas eram recolhidas às cocheiras (aproximadamente $13 \mathrm{~m}^{2}$ ) por volta das 16 horas, e mantidas na luz artificial com lâmpadas de 250 Watts, até as 23 horas, quando então as luzes eram apagadas.

A partir da detecção do cio, foram feitos exames de palpação retal e/ou ultra-sonográficos, duas vezes ao dia, para monitoramento do desenvolvimento folicular, visando a determinar o momento da ovulação e, conseqüentemente, o melhor período para a cobertura. O regime de monta natural foi utilizado para a cobrição das éguas, observando-se os seguintes cuidados: enfaixamento da cauda da égua; higiene da genital externa e perineal; contenção mecânica $e$, se necessário, química ${ }^{2}$ da égua, visando a proteção do garanhão contra eventuais traumatismos; limpeza do pênis do garanhão, após a cópula, com água limpa e morna.

O diagnóstico de gestação foi obtido por meio de palpação retal e/ou ultra-sonografia, a partir do 19 dia após a última cobertura.

Foi realizada tabulação dos dados montando-se as tabelas de freqüência, caracterizando em seguida as medidas de posição e dispersão. A taxa de gestação foi obtida dividindose o número de éguas detectadas como gestantes pelo número total de éguas cobertas e multiplicando-se por 100 . 0 percentual de gestação por estro aproveitado foi calculado dividindo-se o número de éguas prenhes pelo número de estros servidos e multiplicando-se por 100.

Utilizaram-se os procedimentos do "Statistical Analysis System" (SAS, 1990), na avaliação pelo teste de Qui-quadrado para se medir o efeito da época em que as éguas entraram no Posto de Monta (G1 e G2), sobre o percentual de gestação, e dentro dos Grupos para se medir o efeito do fotoperíodo sobre o percentual de prenhez. Foi utilizado o Teste "t" (Student) para avaliar se houve igualdade entre as médias de tempo para que as éguas submetidas ou não à manipulação do fotoperíodo apresentassem o primeiro estro, e também entre as médias do tempo de duração do estro nos Grupos 1 e 2.

\section{Resultados e discussão}

O resultado total da taxa de concepção das éguas que chegaram no Posto de Monta, antes do início (G1) e após iniciada (G2) a estação de monta, encontra-se na Tabela 1.

\footnotetext{
${ }^{2}$ Detomidina - Domocedan (Laboratório Ciba): $20 \mu \mathrm{g} / \mathrm{kg}$ peso vivo.
} 
Tabela 1: Número e percentual de éguas gestantes ou não, total de éguas trabalhadas nos Grupos 1 e 2 e total nos dois Grupos.

\begin{tabular}{|c|c|c|c|c|}
\hline Grupo. & $\begin{array}{l}\text { Eguas } \\
\text { gestantes }\end{array}$ & $\begin{array}{l}\% \text { de } \\
\text { gestac a }\end{array}$ & $\begin{array}{l}\text { Eguas náo } \\
\text { gestantes }\end{array}$ & $\begin{array}{l}\% \text { de nầ } \\
\text { gestantes }\end{array}$ \\
\hline 1 & 63 & $91,3 \%$ & 6 & $8,7 \%$ \\
\hline 2 & 54 & $84,4 \%$ & 10 & $15,6 \%$ \\
\hline TOTAL & 117 & $87,9 \%$ & 16 & $12,1 \%$ \\
\hline
\end{tabular}

O resultado observado no presente estudo pode ser considerado satisfatório, levando-se em consideração os percentuais gerais de gestação em éguas PSI obtidos em outros paíșes, que variam de $61,5 \%$ a $88,7 \%$ em diversas categorias e faixas etárias (BRUCK et al., 1993).

Do total de éguas acompanhadas, 117 (87,9\%) ficaram gestantes. Percentual de gestação semelhante a este, em éguas PSI virgens, foi obtido por Bruck et al. (1993), que conseguiram $87,3 \%$ na Austrália e por Marinho et al. (1994), que alcançaram 88,9\% de prenhez no Brasil.

Bruck et al. (1993) acreditam que o aumento da fertilidade da égua PSI pode estar parcialmente relacionada a um melhor conhecimento da fisiologia da reprodução, associada a disponibilidade de hormonioterapia e de técnicas auxiliares como a ultra-sonografia.

Das éguas com gestação confirmada $(n=117), 63(91,3 \%)$ eram do Grupo 1, e 54 (84,4\%) do Grupo 2, sem diferença $(p>0,05)$ entre os dois grupos, o que justifica dizer que, independentemente da época em que estas éguas chegaram ao Posto, pôde-se obter um índice de fertilidade bastante favorável nesta categoria de éguas virgens. Para tanto, procuramos amenizar o período transicional, desenvolvendo um manejo reprodutivo e nutricional adequados.

O tempo, em dias para o início do primeiro estro, após entrada das éguas no Posto de Fomento e os resultados $(X \pm s)$ obtidos, constam na Tabela 2.

Tabela 2: Média dos quadrados mínimos e respectivo erro-padrão (MQM $\pm E P)$ para aparecimento do 1e estro no $\mathrm{G} 1$ e $\mathrm{G} 2$.

\begin{tabular}{cc} 
Grupo & MQM \pm EP (dias) \\
1 & $23,9 \pm 22,7 d$ \\
2 & $16,0 \pm 16,0 d$ \\
\hline$p>0,05$ &
\end{tabular}

Não houve diferença $(p>0,05)$ entre os dois grupos. A tendência observada de redução do número de dias no Grupo 2, pode dever-se ao período sazonal favorável.

O tempo médio em dias e respectivo desvio padrão para que as éguas submetidas ou não à manipulação do fotoperíodo apresentassem o primeiro estro, nos Grupo 1 e 2 podem ser observados na Tabela 3.
Tabela 3: Média dos quadrados mínimos e respectivo erropadrão $(M Q M \pm E P)$ em dias, para o aparecimento do primeiro estro em éguas submetidas ou não à manipulação do fotoperíodo nos Grupos 1 e 2.

\begin{tabular}{ccc} 
Grupo & $\begin{array}{c}\text { Manipulaçäo do } \\
\text { fotoperiodo }\end{array}$ & $\begin{array}{c}\text { MQM } \pm E P \\
\text { (dias) }\end{array}$ \\
\hline 1 & presente & $17,5 \pm 14,1$ \\
& ausente & $30,4 \pm 31,1$ \\
2 & presente & $14,6 \pm 7,4 \mathrm{~d}$ \\
& ausente & $17,4 \pm 21,8 \mathrm{~d}$ \\
\hline $\mathrm{p}>0,05$ & &
\end{tabular}

A tendência de redução do número de dias para o aparecimento do estro, observada nas éguas do G1 que foram submetidas a tratamento com luz artificial, em relação às do mesmo grupo que não tiveram alteração no fotoperíodo, embora não significativa $(p>0,05)$, revela a importância deste tratamento, uma vez que as éguas deste grupo chegaram ao Posto no período transicional. Além disso, as éguas que foram submetidas à manipulação do fotoperíodo eram justamente aquelas que apresentavam, ao exame, uma inatividade ovariana maior do que as demais do mesmo grupo, fato este que pode ter permitido uma igualdade no percentual de gestação em éguas do Grupo 1.

A duração $(M Q M \pm E P)$ do primeiro estro observado a partir dos sinais de receptividade sexual e/ou do exame ginecológico, nos grupos 1 e 2, está demonstrada na Tabela 4 .

Tabela 4: Duração média do primeiro estro e respectivo erropadrão, demonstrado pelas éguas dos Grupos 1 e 2.

\begin{tabular}{cc} 
Grupo & MQM \pm EP (dias) \\
1 & $6,4 \pm 4,8 d$ \\
2 & $5,9 \pm 4,6 d$ \\
\hline$p>0,05$ & \\
\hline
\end{tabular}

Os resultados foram semelhantes $(p>0,05)$ entre os dois grupos. No G1 a duração do cio foi de 2 a 25 dias $(6,4 \pm 4,8$ d), enquanto no G2 variou de 2 a 37 dias (5,9 4,6 d). Estes tempos de duração dos estros observados estão de acordo com os citados na literatura consultada. Andrade (1983) cita como tempo médio de estro 6 dias, com extremos normais de 2 a 15 dias.

Somente quatro éguas apresentaram o primeiro cio prolongado com o extremo acima da média; entre essas, três éguas eram do Grupo 1 e uma era do Grupo 2. Isto provavelmente ocorreu devido ao fato dessas éguas terem sofrido maior dificuldade em transpor o período transicional e/ ou se adaptar à mudança de ambiente entre o Jockey Club e o Posto de Monta. Porém, três estavam gestantes ao final da estação de monta, o que significa dizer que com o decorrer da temporada a maioria dessas éguas apresentou um ciclo estral normal, apesar do primeiro cio ter sido irregular. 
As 133 éguas acompanhadas foram cobertas durante 196 estros, representando 1,47 estros aproveitados por égua e 1,67 estros aproveitados por gestação, sendo atingida 59,7\% de taxa de concepção por estro aproveitado. Dados semeIhantes a este foram citados por Bruck et al. (1993), que obtiveram 1,61 estros aproveitados por égua, 1,83 estros aproveitados por gestação e $54,7 \%$ de prenhez por estro utilizado.

Das 142 ovulações detectadas, por meio de palpação retal, $75(52,8 \%)$ ocorreram nas 24 horas antes do final do estro e $50(35,2 \%)$ nas 48 horas antes do término do cio. Estas observações estão semelhantes às descrições de Ginther (1979), Andrade (1983), Neely et al. (1983), Adams e Bosu (1988), Mattos (1989), McKinnon et al. (1994), corroborando Quintero et al. (1988), que também trabalharam com éguas $\mathrm{PSI}$ em região do hemisfério sul (tropical). Estes últimos autores verificaram que, das ovulações acompanhadas, $48,1 \%$ ocorreram nas 24 horas e $37,2 \%$ aconteceram nas 48 horas antes do final do cio.

Em relação ao comportamento sexual, observou-se que 10 $(7,5 \%)$ éguas não apresentaram qualquer sinal externo de cio diante do rufião ou de outras éguas no piquete, embora seis éguas tivessem folículos ovulatórios à palpação retal. As quatro éguas restantes foram submetidas a tratamento para indução de cio, com PGF2 $\alpha^{3}$ ou com Altrenogest ${ }^{4}$. Dessas 10 éguas, oito foram cobertas, ficando cinco gestantes e três permaneceram não-gestantes. As duas restantes não chegaram a ser cobertas, por não desenvolverem atividade ovariana. Os animais com cio silencioso, além de estarem ciclando, apresentavam à vaginoscopia um relaxamento do cérvix e hiperemia de mucosa vaginal. Bhuvanakumar et al. (1986) relataram observações semeIhantes em 22 éguas retiradas das corridas, onde $8(36,4 \%)$ não mostraram sinais de cio, embora duas delas estivessem ciclando.

Esses percentuais, embora superiores aos nossos, caracterizam uma situação comum em éguas virgens. $\mathrm{PSI}$, onde o manejo adequado pode ter contribuído na redução dos problemas, possibilitando alcançar resultados expressivos de fertilidade nessa categoria de éguas.

Andrade (1983) e McKinnon (1993) afirmam que éguas virgens e nervosas podem apresentar cio silencioso. Este último autor afirma ainda que exercícios severos e medicamentos geralmente aplicados nas potrancas durante o período de corrida, como anabólicos esteróides, hormônios, antibióticos, corticóides, interferem com atitude sexual, poden-

\section{Referências bibliográficas}

ADAMS, G. P., BOSU, W. T. K. Reproductive Physiology of the Nonpregnant Mare - An Overview and Update. The Veterinary Clinics of North America. Philadelphia : W. B. Saunders Company, v. 4, n. 2, p. 161-176, 1988.

\footnotetext{
3 Lutalyse - UPJOHN
}

4 Regumate - Hoescht do provocar cio silencioso, condições estas comuns aos animais deste experimento, o que pode ter contribuído nos problemas observados.

No que diz respeito ao comportamento das potrancas no momento da cobrição, observamos que entre as 133 éguas trabalhadas, $78(58,6 \%)$ éguas foram cobertas normalmente, sendo que 74 ficaram gestantes e quatro não; outras 31 $(23,3 \%)$ se mostraram tímidas ou assustadas diante do garanhão, mas permitiram a monta por estarem contidas mecanicamente, ficando 25 gestantes e seis não; outras 22 $(16,5 \%)$ éguas só permitiram a monta após serem sedadas quimicamente, sendo que 17 ficaram gestantes e cinco não; as duas éguas restantes não foram cobertas. Esses percentuais são considerados atípicos quando comparados com outras categorias trabalhadas em condições semelhantes neste Posto de Monta.

Bhuvanakumar et al. (1986) em seu estudo também com éguas virgens que encerraram carreira, verificaram resultados em parte semelhantes aos nossos, tendo obtido os seguintes valores: $45,5 \%$ das éguas cobriram normalmente; $22,7 \%$ se apresentaram tímidas; $31,8 \%$ não permitiriam a monta. As diferenças existentes entre os trabalhos podem ser devidas aos manejos adotados e às considerações relativas ao comportamento das éguas que não permitiram a monta. Ambos os trabalhos demonstram, porém, que as éguas virgens da raça PSI podem apresentar um temperamento hostil na ocasião em que realizam a primeira estação de monta, devendo-se, portanto, aplicar um manejo cuidadoso a essa categoria de éguas, evitando, assim, a ocorrência de acidentes e possibilitando a cobertura das mesmas.

\section{Conclusões}

Após encerrarem as atividades turfísticas, éguas que chegam ao Posto de Monta antes do início ou durante a temporada oficial, apresentam taxa de concepção semelhante.

A manipulação do fotoperíodo, aliada a um manejo geral adequado, é importante na indução da atividade cíclica no período transicional quando se trabalha com éguas virgens chegadas diretamente dos hipódromos antes do início da estação de monta oficial.

A taxa de gestação, duração do estro e o momento da ovulação são compatíveis com os descritos previamente na literatura, e o comportamento sexual hostil demonstrado por algumas éguas virgens pode ser contornado com técnicas de manejo adequado.

ANDRADE, L. S. Fisiologia e Manejo da Reprodução Eqüina. Recife : Parque Gráfico da Fábrica de Discos Rozemblit Ltda, 1983. 388 p.

BHUVANAKUMAR, C. K., SATCHIDANADAM, V. Observations on Behavioral Patterns of Maiden Mares. 1 In Oestrus and at Mating. Centaur. India, v. 3, n. 1, p. 25-26, 1986.

BRUCK, I., ANDERSON, G. A., HYLAND, J. H. Reproductive Performance of Thoroughbred Mares on Six Commercial Stud Farms. Australian Veterinary Journal. Australia, v. 70, n. 8, p. 299-303, 1993.

GINTHER, O. J. Reproductive Biological of the Mare: Basic and Applied Aspects. Michigan: Mc Naughan and Gunn, 1979. 
MARINHO, L. A., LOPES, L. A., CARRASCOZA, A. A. T. A. Eficiência Reprodutiva em Éguas Puro-Sangue Inglês (PSI). CONGRESSO DE MEDICINA EQÜINA, 1., 1994, São Paulo. Anais... São Paulo: ARS Veterinária, 1994. p. 245.

MATTOS, R. C. Manejo Reprodutivo da Égua. In: TARANTO, J. C. Sangue e Raça. Rio de Janeiro : Index, 1989. 126 p. v. 1, cap. 9 p. 69-80.
McKINNON, A. O., VOSS, J. L. Equine Reproduction. Malvern : Lea \& Febiger, 1994. $1137 \mathrm{p}$.

NEELY, D. P. ; LIU, I. K. M., HILLMAN, R. B. Equine Reproduction. Philadelphia: Hoffmann-La Roche, 1983.147p.

QUINTERO, B., MANZO, M., DIAZ, T., VERDE, O., BENACHIO, N. SIFONTES, L. Reproductive Behavior of Thoroughbred Mares in a Tropical Enviroment. INTERNATIONAL SYMPOSIUM ONEQUINE REPRODUCTION, 1990. p. 111-112. 